\title{
Mediarte com Amor e Humor: uma Experiência a partir do Olhar dos Participantes
}

\author{
Mediarte with Love and Humor: an \\ Experience from the Participants' Point of \\ View
}

\author{
Karla Patrícia Cardoso Amorim ${ }^{I}$ \\ Ana Kleyce Correia Rocha ${ }^{I}$ \\ Ingrid Cherie Dos Santos Silval \\ Luciana Medeiros Bezerra De Melo \\ Maria Augusta Azevedo De Araújo
}

\section{PALAVRAS-CHAVE}

- Humanização da Assistência;

- Assistência Integral à Saúde;

- Criança Hospitalizada;

- Educação Médica;

- Ética.

\section{KEYWORDS}

- Humanization of Care;

- Comprehensive Health Care;

- Hospitalized Child;

- Medical Education;

- Ethics.
Recebido em: 14/05/2014

Aprovado em: 10/03/2015

\section{RESUMO}

Trata-se de um relato e reflexão a respeito do Projeto MediArte com Amor e Humor, com base nas vivências e percepções das autoras/estudantes integrantes do projeto. O Projeto é uma atividade de extensão da UFRN envolvendo estudantes de medicina. Neste objetiva-se trabalhar a humanização por meio das virtudes humor e amor através de atividades lúdico-recreativas, nas dependências do Hospital de Pediatria da UFRN, envolvendo pacientes, acompanhantes e profissionais semelhantes às intervenções de palhaçoterapia. Busca-se, dentre outros aspectos, resgatar o sorriso e alegria das crianças doentes e promover o cuidado humanizado. Observa-se que a presente iniciativa conforma-se como uma estratégia de educar em saúde, onde teoria e práticas potencialmente interdisciplinares, humanizadoras e éticas são desenvolvidas, contribuindo para uma formação mais integral dos alunos de graduação, bem como uma iniciativa de humanização do cuidado no SUS.

\begin{abstract}
This is a report and a study about the MediArte, with Love and Humor Project, based on the author/ student members' experiences and perceptions. The project is an outreach activity of the UFRN (Federal University of Rio Grande do Norte) involving medicine students. It aims to leverage humanization through the virtues of humor and love, by developing playful and recreational activities in the university pediatric hospital, involving patients, their companions and health care professionals in a process similar to clown-therapy interventions. It also seeks, among other aspects, to retrieve the smile and happiness of sick children and to promote humanized care. It is observed that the initiative represents a health education strategy, in which potentially interdisciplinary, humanizing and ethical theoretical and practical elements are developed, contributing toward a more comprehensive training of undergraduate students, as well as serving as an initiative for humanized care in the SUS.
\end{abstract}




\section{INTRODUÇÃO}

A internação hospitalar pediátrica revela diversas rupturas, mudanças abruptas e impostas, ininteligíveis ao olhar infantil. Ademais, exposta a essa situação de vulnerabilidade, muito além de um corpo doente, vê-se uma mente doente - uma criança que de repente se vê privada do seu aconchego, dos seus brinquedos, das suas brincadeiras, da sua escola, da sua casa, do seu referencial. Uma criança deslocada para um ambiente novo, estranho aos seus olhos, que segue uma rotina, que, por maior discernimento que ela tenha, não representa a leveza e a inocência de costume. E mais, dói, imobiliza, machuca, impede de brincar.

Consequentemente, no processo de hospitalização da criança, são retirados elementos do seu cotidiano referentes ao seu ser, fazer e estar (a sua essência). É imputada a ela uma sequência de atos e/ou procedimentos médicos, que na maioria das vezes não lhe agrada e que ela não tem a opção de escolher. De forma geral, é dessa maneira que são delineadas as experiências de adoecimento vivenciadas pelas crianças nos hospitais.

Aliados a isso, a urgência, a dor e o sofrimento agudos, a iminência da morte, o desconhecido acerca do próprio corpo, a impotência e a necessidade do outro atravessam e constituem o instável e intenso ambiente hospitalar para todos os seus atores ${ }^{1}$. Em se tratando das crianças, a permanência nesse ambiente torna-se ainda mais difícil, pois não há entendimento claro do que esteja ocorrendo.

Por fim, este ciclo de ações e reações experienciado pela criança e familiares gera tensão, estresse e tristeza. Além disso, os sintomas e sentimentos dolorosos intrínsecos ao processo de adoecimento são fontes de maior sofrimento. Por conseguinte, essa realidade, não raro, traduz-se em medo para a criança perante a intervenção da equipe de saúde (o medo do jaleco branco). Todos os aspectos negativos vivenciados podem determinar maior distanciamento e menor colaboração do paciente ${ }^{2}$.

Por reconhecer essa realidade, em que fatores físicos e psicológicos convergem numa carga emocional que pode levar a criança a traumas irreparáveis diante da hospitalização ${ }^{3}$, nota-se a busca crescente pela humanização no âmbito hospitalar com iniciativas desenvolvidas no Brasil e no mundo. Com esse intuito, atualmente, tenta-se alcançar o cuidado humanizado por meio de metodologias que envolvem o lúdico e as artes. Estas ferramentas no hospital têm sido vistas como recursos multidisciplinares positivos, passíveis de uso pelos profissionais de saúde ${ }^{1,2,4-6}$. Esse engajamento, dentre outras finalidades, tem o intuito de tornar a internação infantil menos cansativa e dolorosa, e impedir que o encanto, a alegria e o brilho da infância, na sua essência mais pura, sejam perdidos.
O projeto MediArte com Amor e Humor, objeto deste artigo, foi planejado e desenvolvido nesta perspectiva, sendo apoiado pela Pró-Reitoria de Extensão da Universidade Federal do Rio Grande do Norte (UFRN) como uma contribuição para a humanização do cuidado no Sistema Único de Saúde (SUS). Suas ações acontecem no Hospital de Pediatria Professor Heriberto Ferreira Bezerra da UFRN (Hosped).

A proposta tem como objetivo o exercício das virtudes humor e amor com os alunos de graduação do curso de Medicina UFRN, buscando trabalhar o resgate do cuidado e do sorriso da criança de maneira divertida, aliado ao desenvolvimento de uma formação acadêmica em saúde mais humana e ética. Tem-se como estratégia prática, além dos estudos sobre as virtudes, a realização de atividades lúdicas que promovam o contato e a interação humana com pacientes pediátricos e acompanhantes das enfermarias, de maneira a resgatar o sorriso e a alegria das crianças doentes e promover o cuidado humanizado.

Tal iniciativa é pertinente, visto que, segundo $\mathrm{Mitre}^{7}$, no Brasil, a internação pediátrica responde por cerca de $15 \%$ do total das internações hospitalares - o que significa que mais de um milhão e meio de crianças passam pela experiência de serem hospitalizadas a cada ano. Além disso, a autora alerta: “O impacto que essa experiência pode provocar na vida dessas crianças é uma questão que deve estar presente nas ações em saúde infantil" (p. 283).

O presente artigo tem por intuito relatar e refletir sobre as experiências vivenciadas por suas autoras nas ações de educação e cuidado em saúde infantil do projeto MediArte.

\section{O PROJETO MEDIARTE NO CONTEXTO DA EDUCAÇÃO E HUMANIZAÇÃO DO CUIDADO EM SAÚDE}

As Diretrizes Curriculares Nacionais dos Cursos de Graduação em Medicina ${ }^{8}$, que embasam a atual formação médica, estabelecem que o futuro médico deva ser capacitado a atuar, pautado em princípios éticos, no processo de saúde-doença em seus diferentes níveis de atenção, na perspectiva da integralidade da assistência, com senso de responsabilidade social e compromisso com a cidadania.

Nesse sentido, vê-se que uma formação alicerçada somente em aspectos biológicos e técnicos não dará conta da complexidade que permeia a questão da saúde. Portanto, é imprescindível que, desde o início do curso de graduação, mormente na Medicina, os alunos tenham contato com atividades que trabalhem a ética e as questões da humanização do cuidado nas relações e práticas em saúde. A hipertrofia da razão, em detrimento do sentimento, induz a uma visão utilitarista da vida e a uma dimensão parcial do homem ${ }^{9}$, o que contribui para a construção de uma ciência que, frequentemente, desumaniza e banaliza a vida ${ }^{10}$. 
Pautando-se nessa perspectiva, a ideia do projeto surgiu no segundo semestre de 2009, na disciplina obrigatória Introdução à Medicina e Bioética, do primeiro período do curso de Medicina da UFRN, por ocasião de um seminário sobre a temática das virtudes na Medicina. Nesta atividade de ensino, a bibliografia básica compreendeu o livro Pequeno tratado das grandes virtudes, de autoria de André Comte-Sponville ${ }^{11}$.

Buscando aliar teoria e prática, o grupo responsável pelas virtudes humor e amor, durante o planejamento da sua metodologia de trabalho, decidiu realizar dinâmicas lúdicas interativas com pacientes e acompanhantes das enfermarias do Hosped, inspiradas nas intervenções de palhaçoterapia. Nascia, assim, o MediArte com Amor e Humor.

O Hosped, cenário deste projeto, é integrante do Programa de Humanização da Assistência Hospitalar do Ministério da Saúde. Dessa forma, apresenta como missão assegurar o direito a uma assistência diferenciada, humanizada e de qualidade à clientela infantojuvenil usuária do SUS, assim como o ensino e a pesquisa em saúde da criança e do adolescente.

O projeto é desenvolvido na perspectiva de que o amor, quando presente, mobiliza as demais virtudes espontaneamente $^{11}$. Outrossim, com relação ao humor, entende-se que este "[...] pode fazer rir de tudo, contanto que ria primeiro de $\mathrm{si}^{\prime \prime 11}$ (p. 233); contudo, para ser virtuoso, "[...] é preciso que esse riso acrescente um pouco de alegria, um pouco de doçura ou de leveza à miséria do mundo, e não mais ódio, sofrimento ou desprezo" ${ }^{11}$ (p. 233). Ademais, o sorriso é um indicador de saúde muito importante para o ambiente hospitalar ${ }^{4}$.

Desde sua implantação, observa-se uma repercussão positiva do projeto, de forma que a adesão dos estudantes cresceu a cada ano. O MediArte começou com apenas cinco estudantes e, no decorrer do seu desenvolvimento, foi necessário limitar o número de vagas ao total de 60 participantes (envolvendo estudantes do primeiro ao oitavo período). Junto aos alunos de Medicina, a coordenadora (professora de Bioética do curso de Medicina), um professor da Pediatria, uma psicóloga do Hosped e quatro bolsistas de extensão completam a equipe do projeto. É pertinente destacar que o MediArte recebe a colaboração de outros profissionais desse hospital, como enfermeiros, técnicos de enfermagem e nutricionistas, presentes no momento das intervenções.

Em relação ao apoio institucional, a Pró-Reitoria de Extensão da UFRN apoia o MediArte desde o seu segundo ano de funcionamento, mediante bolsas estudantis e recursos para financiar materiais; e, desde o princípio, classifica-o entre os mais bem avaliados de toda a instituição. Este fato reforça o compromisso da instituição de valorizar iniciativas em conformidade com a Política Nacional de Humanização da Atenção e Gestão (PNH) no SUS.
As intervenções ocorrem durante o período letivo, duas vezes por semana, em grupos compostos por cinco estudantes, em média, responsáveis por desenvolver as atividades. As ações envolvem as crianças internadas (inclusive as restritas aos leitos) e, não raro, contam com a participação de pais e/ou acompanhantes, até mesmo dos de recém-nascidos.

As brincadeiras e atividades são planejadas e executadas de acordo com a idade, o número de crianças levantado previamente e o espaço disponível no Hosped, que contempla a brinquedoteca e as enfermarias. No entanto, comumente, surgem situações no ato das intervenções que demandam modificações do que foi planejado, a exemplo das diversas e inesperadas condições clínicas infantis e diversidades inerentes ao contexto hospitalar. Acredita-se que este fato seja consideravelmente positivo na educação em saúde, por possibilitar o exercício da criatividade e a superação de imprevistos e adversidades quando se trata do ser humano e, principalmente, do processo de cuidar em saúde. Entretanto, o lidar com as incertezas, rotineiramente, é desconsiderado na formação atual, fato que merece urgentemente ser revisto.

Desse modo, o MediArte atualmente desenvolve atividades lúdicas com o intuito de promover o encontro entre os pacientes e os futuros médicos, de maneira a favorecer o exercício do cuidado humanizado e ético, das habilidades relacionais e de comunicação. Diversas são as atividades desenvolvidas nessas intervenções, como: jogos infantis, mímicas, construção de origamis, quebra-cabeças, desenhos e pinturas com situações temáticas, brincadeira de médico e paciente com inversão de papéis, músicas da infância, canções com violão, coreografias encenadas pelos próprios participantes, encenação teatral, apresentação de esquetes improvisados, leitura de histórias, teatro de fantoche, exibição de filmes e vídeos infantis, etc.

Os alunos costumam se maquiar, trajar roupas e acessórios alegres para se caracterizar de palhaços, em concomitância com o jaleco branco, a fim de minimizar a "síndrome do jaleco branco" e, principalmente, possibilitar a aliança entre as virtudes amor e humor no cuidado infantil. Alguns alunos utilizam a metodologia do clown aprendida durante a I Oficina de Iniciação em Clown da UFRN em 2011, fruto de uma parceria com a International Federation of Medical Students Association of Brazil (IFMSA-Brazil), a Proex da UUFR e o Centro de Ciências da Saúde (CSS) da UFRN. Depois dessa iniciativa, outras capacitações para os integrantes do projeto já ocorreram.

Antes e após cada intervenção, o grupo prepara um plano de atuação e um relatório, respectivamente, que são apresentados a todos os integrantes numa reunião, de forma a proporcionar um proveitoso intercâmbio de experiências e aprendi- 
zado. Isto resulta na abordagem e análise de resultados, avaliações, sugestões de metodologias e referenciais teóricos que fundamentam o projeto. Há, também, reflexões sobre os desafios, limitações, expectativas, pontos positivos e negativos vivenciados e, principalmente, as impressões do grupo quanto ao contato humano que teve. As reuniões, portanto, servem para um contínuo aprimoramento da ação, por funcionarem como uma oficina criativa de construção do saber.

\section{A EXPERIÊNCIA A PARTIR DO OLHAR DOS PARTICIPANTES}

Neste momento, busca-se apreender a importância do MediArte a partir das vivências de quatro autoras (estudantes de Medicina integrantes do projeto), tendo por base os registros feitos em seus relatórios, escritos após cada intervenção. Além de trazerem as percepções das autoras/estudantes, esses relatos retratam, de forma indireta, as percepções dos demais atores sociais que vivenciaram esses momentos (profissionais, pacientes do Hosped e seus acompanhantes). Isto porque, em muitas das descrições, será repassado o que as autoras escutaram desses atores durante as intervenções.

Com esse intuito, selecionaram-se trechos dos relatórios que refletem essa experiência como uma oportunidade de envolvimento, reflexão e aprendizado sobre as informações e emoções expressas. Para preservar a identidade das falas das autoras/estudantes, estas receberam nomes de personagens de histórias infantis: Branca de Neve, Cinderela, Chapeuzinho Vermelho e Rapunzel.

De forma geral, observa-se uma avaliação positiva das ações desenvolvidas no projeto. Esse fato foi uma das motivações para que as autoras redigissem este texto autorreflexivo, deixando, assim, registrado que:

"Os resultados da experiência foram maravilhosos, não só para as crianças e seus acompanhantes, como também para nós, que saímos de lá felizes, cansados, mas com um sentimento de recompensa". (Branca de Neve)

"E se para as crianças aquilo foi importante, para nós foi espetacular - conseguir trazer para o nosso curso e futura profissão algo tão importante que é a humanização e ética para com os pacientes [...], não conseguiremos aprender muito disso sentados em uma cadeira em sala de aula". (Cinderela)

É salutar, também, registrar o deslumbramento sentido frente às reações das crianças:

"Muitas crianças davam abraços fortes e beijos inocentes, $e$ dessa forma conseguiam demonstrar o agradecimento; e mui- tos ainda agradeciam com palavras e pediam-nos para voltar mais vezes". (Chapeuzinho Vermelho)

"Fiquei impressionada na visita aos leitos, pois, quando o grupo estava indo embora, uma criança ficou chorando, pois não queria nos deixar sair". (Cinderela)

Verifica-se que os encontros entre as crianças e os estudantes proporcionam um "descobrimento" do poder da atenção e do cuidado. Isso colabora para desmitificar que o domínio da técnica determina o sucesso do cuidado. Por meio de situações simples, porém inusitadas, o MediArte promove o pensar crítico, o questionar das práticas educativas e de saúde no âmbito complexo do hospital.

Nessa mesma perspectiva, de descobrimento do alcance do cuidado humano, é importante registrar dois relatos que abordam relações de qualidade estabelecidas entre as autoras e os pacientes, sendo emblemáticas as falas que seguem:

“Um menino com problema osteolocomotor gostaria muito de ir à Brinquedoteca, mas deveria ficar em repouso no seu leito. Uma de nós ficou jogando quebra-cabeça com ele na enfermaria. [...] a mãe dele elogiou nossa atitude. Disse que aquilo diminuía o tédio que o seu filho sentia por estar direto no hospital, pois seu filho, como toda criança, ama brincar". (Rapunzel)

"R. foi abordada por mim. Sua primeira reação foi correr até a mãe. Esta disse que ela tem receio quando alguém de jaleco branco se aproxima. Esclareci que gostaria de levá-la para a Brinquedoteca [...]; mesmo assim, ficou nítida no olhar sua desconfiança. Perguntei se ela gostava de desenhar e pintar. Ela disse sim. Trouxe ofício e lápis para colorir. Aos poucos, ela foi se soltando, conversando comigo, adquirindo uma fluidez emocional saudável e não parecia mais a menina tímida e desconfiada [...]. Notei que sua confiança comigo estava crescendo. [...] eu também conversava com sua mãe, que disse estar com saudade de casa, que não aguentava mais estar no hospital e estava angustiada por não saber até quando a filha permaneceria lá [...]. No final, me despedi das duas e me senti bem por saber que elas tinham gostado da minha companhia. [...] a mãe elogiou o nosso trabalho. Fiquei feliz. Ela me contou que "foi ótimo, ou melhor, perfeito o que vocês fizeram". [...] Dias depois, disse que, após nosso momento, $R$. demonstrou vontade de ir até a Brinquedoteca, o que ela não tinha demonstrado desde que chegou ao hospital, e pediu para a mãe trazer de casa papel e giz de cera [...], atitude que também não havia tido. A mãe finalizou valorizando as nossas ações para a melhoria da autoestima infantil e que dei- 
xavam as crianças mais felizes naquele ambiente, pois sua filha esquece que é um lugar aonde as pessoas de jaleco branco chegam para "furá-la". Certamente, agora, as pessoas de jaleco branco serão vistas por $R$. como parceiros de brincadeiras também. Quando estava me despedindo de R., ela me abriu um lindo sorriso e disse [...] "tchau, lindinha". Fiquei pensando na $R$. que conheci e a que estava agora diante dos meus olhos: tive a certeza de que é possível fazer muito com tão pouco". (Chapeuzinho Vermelho)

Esse relato demonstra o significativo valor da relação entre profissional de saúde e paciente quando esta é pautada na confiança. Pensar saúde com base no exercício do respeito e da confiança implica tornar a qualidade do contato do paciente tão importante quanto qualquer outro procedimento ${ }^{4}$.

Para os acompanhantes, tais atividades muitas vezes são acalentadoras e reparadoras, uma vez que podem se distrair por alguns instantes, conseguindo mudar o foco do mal que aflige as crianças, e, em algumas ocasiões, desabafar seus anseios e receber palavras de conforto dos participantes do projeto. Notavelmente, observa-se que os acompanhantes percebem que brincar colabora para o bem-estar das crianças em tratamento, aspectos também encontrados por Jesus et al. ${ }^{12}$.

Ainda como parte das reflexões a respeito do educar em saúde na perspectiva da integralidade do cuidado, Franco ${ }^{13}$, ao discutir a qualidade na prática pediátrica em relação ao modelo pedagógico que privilegia o ensino tradicional com enfoque no biomédico, relata que os pediatras participantes de seu estudo reconheceram que a escola médica não propiciou a ampliação do núcleo de atuação do médico. Assim, durante este modelo dominante de educação, o estudante estaria impedido de perceber que o processo de atenção e cuidado é também tecnologia e deve ser aprimorado com a incorporação de elementos como vínculo, responsabilização, troca e comunicação. Neste caso, fala-se em tecnologia leve, que ocorre no espaço intersubjetivo entre profissional e usuário, sendo essencialmente relacional e processual ${ }^{14}$, o que abrange escuta, acolhimento, expectativas, afetações e processos vinculativos provocados pelo encontro dos atores envolvidos ${ }^{1}-$ aspectos exercitados no MediArte.

O projeto, quando planejado, tinha o objetivo de atingir os pacientes e estudantes, mas, potencialmente, demonstrou um alcance maior - envolve os pais e/ou acompanhantes das crianças e a equipe de profissionais do Hosped. Ao observarem as ações, os profissionais são provocados a refletir sobre suas práticas ${ }^{4}$. Normalmente, segundo as percepções das autoras/estudantes, esse conjunto de atores sociais também avalia o MediArte de forma positiva. Nesse sentido, vale compar- tilhar algumas impressões a respeito do projeto, obtidas em conversas com as enfermeiras e residentes do Hosped durante as intervenções:

"As enfermeiras do hospital nos contaram que as mães reconhecem a importância do projeto, pois as crianças ficam bastante ansiosas para a chegada dos "palhacinhos" e pelo fim de semana. O sábado e o domingo são os dias mais especiais. De manhã logo cedo, elas já ficam prontas e arrumadinhas para ir para a teca (brinquedoteca) e, depois da intervenção, elas ficam $100 \%$ e passam o resto do dia ativas. L., de 11 anos [...], disse a uma das enfermeiras que gostava muito quando os "palhacinhos" vinham porque brincando esquecia que estava doente". (Cinderela)

"Já outra profissional nos relatou a história de um menino que tinha problema de equilíbrio ao andar, mas, enquanto estava com os palhacinhos, notou que ele despercebidamente conseguiu andar normal. E, quando chamou sua atenção, ele disse: "realmente, esqueci que estou doente". Ela destacou como foi impressionante". (Rapunzel)

"Os residentes do Hosped avaliam com bons elogios nossas manhãs junto às crianças. Esses profissionais concluíam que, como os palhacinhos ficam de jaleco branco, elas enxergam neles os palhacinhos que vão levá-las para a "teca", o que dá mais harmonia à relação profissional-paciente; inclusive, porque elas costumam enxergar nos profissionais pessoas que vão furá-las e estigmatizam isso, ficam com medo. Então, o projeto ajuda a quebrar esse preconceito". (Chapeuzinho Vermelho)

"Uma das residentes presentes certa vez nos abordou dizendo que seria importante ampliar e dar visibilidade ao projeto, para que outros alunos viessem mais vezes e outras universidades pudessem aderir à mesma ideia". (Branca de Neve)

A promoção do brincar - um recurso seguro e acessível à criança - possibilita integrar a experiência de estar no hospital como parte de sua vivência, o que subsidia uma adaptação positiva e ativa na vivência da rotina hospitalar ${ }^{15}$. Assim, o brincar tende a minimizar os impactos da internação no cotidiano da criança, em seu desenvolvimento e nas trocas sociais ${ }^{1}$, pois auxilia a criança a compreender e a elaborar o momento particular que vive no hospital, o que diminui as condições negativas e possibilita maior inclusão da mesma na instituição ${ }^{2}$. Esses foram aspectos já mencionados nos depoimentos supracitados e reforçados nas seguintes reflexões:

"As brincadeiras e a arte proporcionam distração, divertimento, alegria, e acabam contribuindo com a realização 
dos procedimentos clínicos de modo a facilitar o trabalho da equipe de saúde e a reabilitação da criança hospitalizada, ao melhorar significativamente a autoestima dela". (Branca de Neve)

"[...] o brincar é um importante instrumento para garantir a continuidade do tratamento, capaz também de promover o desenvolvimento infantil, pois o brincar parece um sinal saudável e preservado, apesar da doença". (Cinderela)

Além da possibilidade de melhorar o estado emocional da criança, propiciar um aprendizado sobre a condição humana e estabelecer relações de qualidade, as ações desenvolvidas pelo MediArte podem inseri-lo no rol de novas estratégias que começam a se desenvolver de forma a resgatar para o sujeito (paciente) o lugar de protagonista das ações em saúde e a desenvolver uma cotidianidade diferenciada nos ambientes hospitalares que reinscreva o processo de adoecimento como parte integrante da vida ${ }^{1}$.

Assim, o projeto poderá constituir uma estratégia de educação ética, visto que o período de internação pode, inclusive, "ser aproveitado para apoiar o paciente na direção de conquistar maior autonomia e na reconstrução de seu modo de andar a vida"16 (p. 204). Dessa forma, dentre outros aspectos, o brincar pode devolver a condição de atividade (em oposição à passividade), pois a criança não se contenta em contemplar as imagens; ela as manipula na brincadeira e, ao fazê-lo, transforma-as e reinventa o real, dá-lhe novas significações, transformando-o numa experiência possível do viver ${ }^{17,18}$. Sob essa perspectiva, Angeli et al. ${ }^{1}$ ressaltam que o brincar abre, para crianças e adolescentes, e também para todos os demais envolvidos no processo, a condição permanente de reinventar o presente, a realidade e a si mesmo, permitindo a modificação da realidade e de valores socioculturais.

O contexto complexo do hospital é um espaço que extrapola o contexto técnico e da doença, constituindo um espaço de alcance sociopolítico, de acesso e manipulação de conteúdos diversos, a ser reinventado permanentemente pelo fato de ser composto por elementos subjetivos e socioculturais ${ }^{1,19}$. Este entendimento é ancorado, de certa forma, no relato de uma das autoras sobre este comentário de uma das acompanhantes:

\footnotetext{
"Uma mãe que nos acompanhava durante um dia de brincadeiras acredita que nosso trabalho ajuda muito as crianças a se recuperarem. De acordo com ela, as atividades diminuem a tensão com os profissionais e quebram a tristeza do hospital, além de serem ações educativas, que muitas mães não têm instrução suficiente para tal". (Branca de Neve)
}

Igualmente, o local utilizado em muitas iniciativas semelhantes à analisada no presente artigo - a brinquedoteca - é um espaço onde as crianças e adolescentes aprendem a compartilhar brinquedos, histórias, emoções, alegrias e tristezas sobre a condição de hospitalização, o que propicia desenvolverem aspectos de socialização e cidadania ${ }^{2}$. Desenha-se, assim, um espaço real de possibilidade de troca e construção de redes relacionais, onde se mobiliza a produção de algo em comum $^{1}$. Segundo Mitre e Gomes ${ }^{20}$, “a promoção do brincar no espaço da hospitalização infantil configura-se, então, como facilitador de uma dinâmica de interações que (re)significa o modelo tradicional de intervenção e cuidado de crianças hospitalizadas" (p. 8).

As crianças demonstram zelo e cuidado no manuseio dos brinquedos, reforçando os aspectos de cidadania desenvolvidos no ambiente. Há uma intensa interação entre as crianças e o profissional responsável, o que fortalece o vínculo entre a criança e a instituição - o que também é relatado no estudo de Angelo e Vieira ${ }^{2}$. Assim, é pertinente registrar, com base no que se escuta durante as intervenções por parte dos profissionais e responsáveis pelas crianças, o desejo de irem à brinquedoteca, ambiente extremamente rico de possibilidades, e os sentimentos de alegria e contentamento durante as atividades, sendo emblemático este registro:

\footnotetext{
"A avó contou que, durante a visita diária, a médica pediu a L., sua neta, que escolhesse um presente; como resposta, ela disse que queria "a teca", referindo-se à brinquedoteca. Isso mostra o quanto esse tipo de atividade é importante para crianças como L". (Rapunzel)
}

Embora sejam inegáveis os benefícios da medicina tecnocientífica, dotada apenas de razão, esta fica mutilada da dimensão humana. $\mathrm{O}$ alcance de uma educação que busque o exercício de competências que vão além da técnica pode ser percebido nesta reflexão de uma das autoras/estudantes sobre um dia de atividade no projeto:

"Observei a satisfação dos pais e profissionais ao vê-las brincando e interagindo com outras crianças e adultos, podendo compartilhar um momento de distração e distanciamento do motivo que as levou à hospitalização. O MediArte ajuda os estudantes a terem uma visão mais crítica da vida das crianças e da importância da remodelação do ambiente hospitalar. Desde nossa entrada na enfermaria para mais uma ação, percebemos que um dos pacientes com quadro de paralisia de hemicorpo chorava muito e não queria participar das brincadeiras. Após tentarmos interagir com ele e sua mãe, aos 
poucos, foi ficando mais calmo, sorrindo e brincando conosco. Durante uma das brincadeiras, ele ficou encantado com os cabelos da fantoche "Maricota", segurou o pente que estava em cima da cama e tentou penteá-la, movendo pela primeira vez seu braço depois do internamento... Foi um momento de muita alegria e emoção da mãe e para nós. Mais uma prova do poder do Amor e do Humor". (Chapeuzinho Vermelho)

Por fim, esta discussão, embora não esgote a temática, aponta a complexidade do educar e cuidar em saúde. Vários autores têm enfatizado que a mudança de cenário, simplesmente, não garante a formação de um profissional capaz de reconhecer e atuar considerando as necessidades de saúde da população ${ }^{21-25}$. Assim, evidencia-se a importância de estudos e relatos como este do MediArte, que sinalizem o que é necessário do ponto de vista do ensino e prática em saúde para alcançar transformações no perfil do profissional que se está formando, buscando melhorar a qualidade do cuidado integral em saúde.

\section{CONSIDERAÇÔES FINAIS}

A presente iniciativa representa uma estratégia de educar e cuidar em saúde que reforça a perspectiva de humanização do SUS, em que teoria e práticas potencialmente interdisciplinares, humanizadoras e éticas são desenvolvidas com vista a contribuir para uma formação mais integral dos alunos de graduação, com extensão, também, aos profissionais de saúde.

A realização das intervenções desperta para a importância da vivência e aplicação dos valores e condutas humanistas pelos estudantes. Isto porque transpõe a intenção ao promover o gesto, mediante ações relativamente simples, porém com alcance imensurável.

Além disso, o MediArte possibilita uma aproximação maior entre cuidadores e pacientes, uma vez que minimiza a "síndrome do jaleco branco" e colabora para uma internação infantil menos cansativa e dolorosa.

O projeto ainda aponta uma visão crítica do ambiente hospitalar e do processo de hospitalização, que apresentam potencial para o exercício ético e político por avivarem o desenvolvimento da cidadania e da autonomia dos sujeitos.

Desse modo, almejou-se proporcionar uma reflexão acerca dos verdadeiros aspectos da palavra cuidar, fundamentados nas virtudes basilares amor e humor, as quais, vinculadas à doçura, têm a capacidade de curar, libertar e transmutar a tristeza em alegria.

Este trabalho, portanto, embora não pretenda esgotar as questões envolvidas na temática da humanização em saúde, configura-se como um caminho e possibilidade reais de sua prática.

\section{REFERÊNCIAS}

1. Angeli AAC, Luvizaro NA, Galheigo SM. O cotidiano, o lúdico e as redes relacionais: a artesania do cuidar em terapia ocupacional no hospital. Interface (Botucatu). 2012;16(40):261-72.

2. Angelo TS, Vieira MRR. Brinquedoteca hospitalar: da teoria à prática. Arq Ciênc Saúde.2010;17(2):84-90.

3. Santa Roza E. Um desafio às regras do jogo. In: Santa Roza E; Reis ES (Org). Da análise na infância ao infantil na análise. Rio de janeiro: Ed Contracapa; 1997. p.161-188.

4. Masetti M. Ética da alegria no contexto hospitalar. 1 ed. Rio de Janeiro: MMD; 2011.

5. Pedrosa AM, Monteiro H, Lins K, Pedrosa F, Melo C. Diversão em movimento: um projeto lúdico para crianças hospitalizadas no Serviço de Oncologia Pediátrica do Instituto Materno Infantil Prof. Fernando Figueira, IMIP. Rev Bras Saude Matern Infant 2007; 7(1):99-106.

6. Furtado MCC, Lima RAG. Brincar no hospital: subsídios para o cuidado de enfermagem. Rev esc enferm USP.1999;33(4):364-9.

7. Mitre RMA. O brincar no processo de humanização da produção de cuidados pediátricos. In: Deslandes SF (Org) Humanização dos cuidados em saúde - conceitos, dilemas e práticas. Rio de Janeiro: Ed FIOCRUZ; 2006. p.283-300.

8. Brasil. Ministério da Educação. Conselho Nacional de Educação. Câmara de Educação Superior. Resolução CNE/ CES n ${ }^{\circ} 4$ de 7 de novembro de 2001. Institui diretrizes curriculares nacionais do curso de graduação em medicina, Diário Oficial da União. Brasília, 9 nov. 2001. Seção 1, p. 38.

9. Boff L. Saber Cuidar: ética do humano, compaixão pela terra. Petrópolis: Ed. Vozes; 2004.

10. Morin E. Ciência com Consciência. 4 ed. Rio de Janeiro: Ed Bertrand Brasil; 2000.

11. Comte-Sponville A. Pequeno tratado das grandes virtudes. São Paulo: Editorial Presença; 1995.

12. Jesus IQ, Borges ALV, Pedro ICS, Nascimento LC. Opinião de acompanhantes de crianças em quimioterapia ambulatorial sobre uma quimioteca no Município de São Paulo. Acta paul enferm.2010;23(2):175-80.

13. Franco SC. A qualidade possível: o pediatra e o processo de decisão médica nos serviços públicos de saúde. Campinas; 2001. Doutorado [Tese] - Faculdade de Ciências Médicas, Universidade Estadual de Campinas.

14. Mehry EE. Saúde: a cartografia do trabalho vivo. São Paulo: Ed Hucitec; 2002.

15. Morais ISN. O brincar na construção de um cuidado integral à criança hospitalizada. Anais do II Encontro Nacional de Bioética e Biodireito. III Encontro de Comitês de ética 
em Pesquisa da Paraíba. 2009 out. 08 - 10. João Pessoa, Brasil. João Pessoa:UFPB; 2009. p.319-30.

16. Cecílio L, Merhy EE. Integralidade do cuidado como eixo da gestão hospitalar. In: Pinheiro R, Mattos RA, Camargo $\mathrm{K}$, (Org). Construção da integralidade, cotidiano, saberes e práticas em saúde. Rio de Janeiro: Ed Abrasco; 2003. p.197210.

17. Rossit RA, Kovács AC. Intervenção essencial de terapia ocupacional em enfermaria pediátrica. Cad Ter Ocup UFSCar 1998; 7(2):58-67.

18. Brougère G. Brinquedo e cultura. São Paulo: Cortez; 1995.

19. Brougère G. A criança e a cultura lúdica. In: Kishimoto TM, org. O brincar e suas teorias. São Paulo: Pioneira; 2002. p. 19-32.

20. Mitre RMA, Gomes R. A promoção do brincar no contexto da hospitalização infantil como ação de saúde. Cienc Saude Colet 2004; 9(1):147-154.

21. Prearo AY, Rizzato ÁBP, Martins STF. O ensino de pediatria na atenção básica em saúde entre as fronteiras do modelo biomédico e a perspectiva da integralidade do cuidado: a visão dos médicos supervisores. Interface (Botucatu) 2011;15(39):1039-51.

22. Pontes AL, Rego S, Silva Junior AG. Saber e prática docente na transformação do ensino médico. Rev Bras Educ Med 2006; 30(2):66-75.
23. Bulcão LG. O ensino médico e os novos cenários de ensino-aprendizagem. Rev Bras Educ Méd.2004;28(1):61-72.

24. Garcia MAA. Saber, agir e educar: o ensino-aprendizagem em serviços de Saúde. Interface - Comunicação, Saúde, Educação. Interface (Botucatu).2001;5(8):89-100.

25. Feuerwerker L. Mudanças na educação médica e residência médica no Brasil. Interface (Botucatu).1998;2(3):51-71.

\section{CONTRIBUIÇÃO DOS AUTORES}

As autoras trabalharam juntos em todas as etapas de produção do manuscrito.

\section{CONFLITO DE INTERESSES}

As autoras declaram não haver conflito de interesses.

\section{ENDEREÇO PARA CORRESPONDÊNCIA}

Karla Patrícia Cardoso Amorim

Centro de Ciência da Saúde - Hospital Universitário Onofre Lopes -

Departamento de Medicina Clínica

Av. Cordeiro de Farias s/n

Petrópolis - Natal

CEP 59012-300 RN

E-mail: amorimkarla@yahoo.com.br 